\title{
Study of the Emitted Dose After Two Separate Inhalations at Different Inhalation Flow Rates and Volumes and an Assessment of Aerodynamic Characteristics of Indacaterol Onbrez Breezhaler ${ }^{\circledR} 150$ and $300 \mu \mathrm{g}$
}

\author{
Mohamad Abadelah, ${ }^{1}$ Henry Chrystyn, ${ }^{2}$ Golshan Bagherisadeghi, ${ }^{1}$ Gaballa Abdalla, ${ }^{3}$ and Hassan Larhrib ${ }^{1,4}$
}

Received 28 February 2017; accepted 21 June 2017; published online 10 July 2017

\begin{abstract}
Onbrez Breezhaler ${ }^{\circledR}$ is a low-resistance capsule-based device that was developed to deliver indacaterol maleate. The study was designed to investigate the effects of both maximum flow rate (MIF) and inhalation volume (Vin) on the dose emission of indacaterol 150 and $300 \mu \mathrm{g}$ dose strengths after one and two inhalations using dose unit sampling apparatus (DUSA) as well as to study the aerodynamic characteristics of indacaterol Breezhaler ${ }^{\circledR}$ using the Andersen cascade impactor (ACI) at a different set of MIF and Vin. Indacaterol 150 and $300 \mu \mathrm{g}$ contain equal amounts of lactose per carrier. However, $150 \mu \mathrm{g}$ has the smallest carrier size. The particle size distribution (PSD) of indacaterol DPI formulations 150 and $300 \mu \mathrm{g}$ showed that the density of fine particles increased with the increase of the primary pressure. For both strengths $(150 \mu \mathrm{g}$ and $300 \mu \mathrm{g})$, ED1 increased and ED2 decreased when the inhalation flow rate and inhaled volume increased. The reduction in ED1 and subsequent increase in ED2 was such that when the Vin is greater than $1 \mathrm{~L}$, then $60 \mathrm{~L} / \mathrm{min}$ could be regarded as the minimum MIF. The Breezhaler was effective in producing respirable particles with an MMAD $\leq 5 \mu \mathrm{m}$ irrespective of the inhalation flow rate, but the mass fraction of particles with an aerodynamic diameter $<3 \mu \mathrm{m}$ is more pronounced between 60 and $90 \mathrm{~L} / \mathrm{min}$. The dose emission of indacaterol was comparable for both dose strengths 150 and $300 \mu \mathrm{g}$. These in vitro results suggest that a minimum MIF of $60 \mathrm{~L} / \mathrm{min}$ is required during routine use of Onbrez Breezhaler ${ }^{\circledR}$, and confirm the good practice to make two separate inhalations from the same dose.
\end{abstract}

KEY WORDS: aerodynamic dose emission characteristics; indacaterol; Onbrez Breezhaler ${ }^{\mathbb{R}}$; inhalation volume; maximum inhalation flow.

\section{INTRODUCTION}

Inhaled therapy is the mainstay treatment of choice to control the symptoms of asthma and chronic obstructive pulmonary disease (COPD) (1) using either metered dose inhalers (MDIs) or dry powder inhalers (DPIs). The quality and the amount of the emitted dose from a DPI depend on the patient's inhalation manoeuvre, the type of device and its formulation $(2,3)$. Each inhalation manoeuvre is characterised by a flow versus time profile which

Electronic supplementary material The online version of this article (doi:10.1208/s12249-017-0841-y) contains supplementary material, which is available to authorized users.

\footnotetext{
${ }^{1}$ Department of Pharmacy and Pharmaceutical Sciences, University of Huddersfield, Queensgate, Huddersfield, HD1 3DH, UK.

${ }^{2}$ Inhalation Consultancy Ltd, Yeadon, Leeds, LS19 7SP, UK.

${ }^{3}$ Department of Engineering and Technology, University of Huddersfield, Huddersfield, HD1 3DH, UK

${ }^{4}$ To whom correspondence should be addressed. (e-mail: e.larhrib@hud.ac.uk)
}

includes the inhaled volume. During use, inhalation flow interacts with the resistance inside the DPI to generate a 'force' that deaggregates the formulation such that active drug particles, with the greatest likelihood of lung deposition, are entrained in the air stream as it leaves the device. The inhaled volume ensures that the dose is emptied from the metering cup/capsule (the latter applies if the DPI is a single-dose capsule product). When inhaling from a single-dose capsule DPI product, it is essential that the inhaled volume is sufficient to empty the entire dose out of the capsule. It is for this reason that the patient information leaflet (PIL) for these DPIs should direct patients to make two separate inhalation manoeuvres from each prepared capsule dose $(1,4)$.

The resistance of a DPI is an intrinsic value which depends on the design of the inhalation channel, the metering cup and the air inlets (5). DPIs can be classified into four resistance groups (low, medium, medium-high, high) with respect to the inhalation flow required to produce a pressure drop of $4 \mathrm{kPa}(1,6)$. Patient inhalation flows through highresistance devices are naturally lower than those having a 
lower resistance (7-10). However, the internal 'force' created by a low flow through a DPI with high resistance is higher than that created by a faster flow through a DPI with low resistance (11). The Breezhaler ${ }^{\circledR}$ is a low-resistance device and has a resistance of $0.0177(\mathrm{kPa})^{0.5}\left(\mathrm{~min} \mathrm{~L}^{-1}\right)(6)$.

Patients with COPD have reduced inspiratory capacities together with low inhaled volumes (12), and so many use suboptimal inhalations when using DPIs which means that the dose they inhale is reduced.

Inhalers play an important role in the management of patients with COPD, and it is being recognised that the choice of the inhalation device appears to be as important as that of the drug molecule $(8,13)$. Inhaled long-acting bronchodilators are used for the treatment of patients with moderate and more severe COPD (14), and now, agents are available for once-daily administration. Indacaterol is an inhaled, once-daily, ultra-long-acting $\beta 2$-agonist (15). The indacaterol is mixed with lactose (to increase the bulk and enhance powder flow of the formulation). It is packaged in transparent hard gelatine capsules each containing either 75, 150 or $300 \mu \mathrm{g}$ of indacaterol inhalation powder inhaled from a Breezhaler ${ }^{\circledR}$ inhaler. Published data shows that patients with stable COPD were able to generate, on average, a maximum inhalation flow (MIF) of $72 \mathrm{~L} / \mathrm{min}$ with a range of $47-99$ to 94.8 L/min (range, $52-133 \mathrm{~L} / \mathrm{min}$ ) and mean inhaled volumes (Vin) of $1.7 \mathrm{~L}$, range of 1 to $2.2 \mathrm{~L}(8,16,17)$. In vitro dose emission studies focus on identifying the optimal inhalation flow rate for dose deaggregation; however, this optimal flow may not be achievable in real-life use by the patient. The multivariate statistical approach study carried out by Buttini et al. demonstrates that the fine particle mass emitted from the single-dose inhaler device has significantly decreased when the minimum inspiratory volume was used to operate the device (18). The information that is most clinically relevant is to identify the type of dose emitted when low inhalation flows and inhaled volumes are used. This is very important for patients with COPD because these patients can only use low inhalation flows and low inhaled volumes $(11,12)$. Therefore, the primary aim of this work was to investigate a range of inhalation flow rates $(28.3,60,90$ and $120 \mathrm{~L} / \mathrm{min})$ and volumes (500, 750, 1000, 1500 and $2000 \mathrm{~mL}$ ) on the dose emission from 150 and $300 \mu \mathrm{g}$ indacaterol Onbrez Breezhaler ${ }^{\circledR}$ (Novartis Pharmaceuticals Ltd., UK) using two separate inhalations. Secondly, this study was conducted to determine the aerodynamic characteristics of indacaterol emitted dose using the Andersen cascade impactor (ACI) at a MIF of 28.3, 60 and $90 \mathrm{~L} / \mathrm{min}$ and 1, 1.5, 2 and $4 \mathrm{~L}$ inhaled volumes.

\section{MATERIAL AND METHODS}

Characterisation of the Indacaterol Onbrez Breezhaler ${ }^{\circledR} 150$ and $300 \mu \mathrm{g}$ Powder Formulations by Scanning Electron Microscope

Scanning electron microscopy (SEM) investigations of the shape, particle size and surface texture of indacaterol and the lactose in the Onbrez Breezhaler ${ }^{\circledR} 150$ and $300 \mu \mathrm{g}$ (Novartis Pharmaceuticals, $\mathrm{CH}$ ) products were carried out using a Jeol 6060LV SEM (Jeol Ltd., UK). A sample of the powder formulation was scattered onto the aluminium stage stub, by a gentle tapping motion to provide a thin layer that was suitable to view the particles. The movement of the sample was restricted by adhering the sample to a double-sided conductive carbon adhesive tape (Agar Scientific, UK). As the sample is non-conductive, it was required to coat the sample with a thin layer of gold (15-20 nm) (Quorum Technologies Ltd., UK) using a Quorum SC7620 sputter coater (Quorum Technologies Ltd., UK).

\section{Particle Size Measurement Using Dry Dispersion Laser Diffraction}

Particle size measurements were carried out using a Sympatec HELLO/RODOS (Sympatec GmbH, ClausthalZellerfel, Germany). The methodology used was similar to the one reported by Jaffari et al. except that the primary range employed was in the range of $0.12-4.51$ bar to investigate the indacaterol Breezhaler particle distribution density when the primary pressure changed (19).

\section{Chemicals and Solvents}

Indacaterol maleate (analytical grade) was purchased from Medchem (USA). Potassium dihydrogen orthophosphate, orthophosphoric acid and methanol high-performance liquid chromatography (HPLC) grade were obtained from Fisher Scientific (UK). The water was ultra-purified for HPLC use. Indacaterol Onbrez Breezhaler ${ }^{\circledR}$, a nominally labelled dose of $150 \mu \mathrm{g}$ (batch number B0018; expiry date 04/ 2016) and $300 \mu \mathrm{g}$ (batch number B0011; expiry date 08/2016) indacaterol maleate per dose in a size 3 transparent hard gelatine capsule (Novartis Pharmaceuticals, $\mathrm{CH}$ ), was obtained from a local supplier and so were those available for patient use. The amount of lactose in both formulations is almost the same-24.8 and $24.6 \mathrm{mg}$ for both 150 and $300 \mu \mathrm{g}$ dose strengths, respectively.

\section{Dose Emission, Residual Amount and Recovered Dose from 150 and $300 \mu \mathrm{g}$ Onbrez Breezhaler ${ }^{\circledR}$ DPIs}

The total emitted dose (TED) was determined using a DPI dose unit sampling apparatus (DUSA, Copley Scientific, UK) after two separate inhalations. The dose of 150 or $300 \mu \mathrm{g}$ indacaterol maleate emitted from an Onbrez Breezhaler ${ }^{\circledR}$ was determined using the DPI dose emission method described in the pharmacopoeia (20) except that a range of flows and volumes have been used instead of the flow that produces a 4$\mathrm{kPa}$ pressure drop and inhaled volume of $4 \mathrm{~L}$. For each determination, two DUSAs (Copley Scientific Ltd., UK) were used so that the dose emitted from the first inhalation (ED1) and a second inhalation (ED2) could be measured separately. ED1 and ED2 were summed to provide the TED. The emitted dose from the Onbrez Breezhaler ${ }^{\circledR}$ inhalers was measured by collecting one individual dose at different MIFs and Vins. For each determination, one capsule was inserted into the device according to the manufacturer's instructions in the PIL. For each inhalation flow, the emitted dose of three separate, single unit capsule doses was determined $(n=3)$. Following each dose emission into the DUSA, the emitted dose was recovered using an acetonitrile:water (60:40 v/v) 
solution. The filter was immersed into an appropriate volume of this washing solution and then sonicated for $15 \mathrm{~min}$ to detach and dissolve the indacaterol entrained on the filter. After the second inhalation, the device and capsules were washed separately to determine any residual amount left in the capsules $\left(\mathrm{RA}_{\mathrm{CAP}}\right)$ and device $\left(\mathrm{RA} \mathrm{A}_{\mathrm{DEV}}\right)$. The total residual amount (TRA) was calculated by summing $\mathrm{RA}_{\mathrm{CAP}}+\mathrm{RA}_{\mathrm{DEV}}$. The total recovered dose (TRD) was calculated as the sum of the TED + TRA.

\section{Determination of the Aerodynamic Characteristics of the Emitted Dose and Collection of the Residual Amount of Indacaterol}

The aerodynamic characteristics of indacaterol 150 and $300 \mu \mathrm{g}$ from an Onbrez Breezhaler ${ }^{\circledR}$ were determined at MIF values of 28.3, 60 and $90 \mathrm{~L} / \mathrm{min}$ with Vin values of 1, 1.5, 2 and $4 \mathrm{~L}$ using the Andersen Cascade Impactor (ACI) and the USP throat. At $28.3 \mathrm{~L} / \mathrm{min}$, standard ACI stages from 0 to 7 were used, whilst to enable ACI to operate at $60 \mathrm{~L} / \mathrm{min}$, stages 0 and 7 were replaced with stages -1 and -0 . To enable determinations at $90 \mathrm{~L} / \mathrm{min}$, stages $-2 \mathrm{~A},-1 \mathrm{~A}$ and -0 were used instead of stages 0,6 and 7. The stages' cut-off diameters at $28.3 \mathrm{~L} / \mathrm{min}$ MIF in descending order were 9.0, 5.8, 4.7, 3.3, 2.1, 1.1, 0.7 and $0.4 \mu \mathrm{m}$, respectively. At $60 \mathrm{~L} / \mathrm{min}$, the stages' cut-off diameters were 8.6, 6.5, 4.4, 3.2, 1.9, 1.2, 0.55 and $0.26 \mu \mathrm{m}$. At $90 \mathrm{~L} / \mathrm{min}$, the stages' cut-off diameters were 8.0, $6.5,5.2,3.5,2.6,1.7,1.0$ and $0.22 \mu \mathrm{m}$. For each calibrated flow rate $(28.3,60$ and $90 \mathrm{~L} / \mathrm{min})$, a designed pre-separator was connected to the ACI. The collection plates were sprayed with silicone lubricant (Pro-Power Premier Farnell plc, UK) and allowed to dry at room temperature before use. The ACI was connected to a vacuum pump (HCP, Copley Scientific Ltd., UK) via the critical flow controller (model TPK Copley Scientific Ltd., UK). The ACI stages were assembled with $10 \mathrm{~mL}$ of $60 \%$ methanol:40\% ultra-purified water $(\% v / v)$ in the pre-separator, and a glass fibre GF50 (Whatman, UK) filter was placed in the final stage. For each determination, three capsules from $150 \mu \mathrm{g}$ were used, and for indacaterol $300 \mu \mathrm{g}$, only two capsules were used. Each dose was prepared according to the manufacturer's recommended patient instructions (in the PIL). Three separate determinations were made for each dose strength using MIF values of 28.3, 60 and $90 \mathrm{~L} / \mathrm{min}$ at Vins of 1, 1.5, 2 and $4 \mathrm{~L}$. The residual amount was determined by washing the capsules and device separately using $10 \mathrm{~mL}$ of the washing solution.

\section{HPLC Quantification of Indacaterol}

After each determination, the mouth piece adaptor (MP), induction port (IP), ACI collecting plates, capsules and device were separately rinsed with various volumes of the acetonitrile $60 \%$ :water $40 \%$ washing solution: MP $(5 \mathrm{~mL})$, IP $(10 \mathrm{~mL})$, pre-separator $(20 \mathrm{~mL})$, collecting plates, the ACI filter, capsules and device $(10 \mathrm{~mL}$ each) of the washing solution containing $60 \%$ methanol: $40 \%$ ultra-purified water $(v / v)$. The amount of indacaterol from these washings was determined using a validated HPLC method. The chromatographic separation was performed at $40^{\circ} \mathrm{C}$ using a $\mathrm{C} 18$ Kinetex $(250 \mathrm{~mm} \times 4.6 \mathrm{~mm}, 5 \mu \mathrm{m})$ column $\left(\right.$ Phenomenex ${ }^{\circledR}$, USA). The mobile phase was methanol:buffer $(25 \mathrm{mM}$ potassium dihydrogen orthophosphate $60: 40 \% v / v$ ). Before use, the mobile phase was filtered through a membrane filter ( $47 \mathrm{~mm}$ diameter, pore size $0.45 \mu \mathrm{m}$ ). The mobile phase was delivered at a flow rate of $1 \mathrm{~mL} / \mathrm{min}$; the injection volume was $20 \mu \mathrm{L}$, UV detection at $259 \mathrm{~nm}$ (D200, Shimadzu, Japan) and a run time of $7 \mathrm{~min}$. The detector response was shown to be linear over the range of $0.1-10 \mu \mathrm{g} / \mathrm{mL}$. Each solution was injected in triplicate. The response for indacaterol concentrations gave a correlation coefficient that identified linearity $(r(2)=0.99 ; y=2.0515 x-0.0006 ; n=9)$. The limit of detection (LOD) and limit of quantification (LOQ) for indacaterol were 0.05 and $0.17 \mu \mathrm{g} / \mathrm{mL}$, respectively.

\section{Measurement of Dose Uniformity}

The indacaterol content and uniformity in the 150- and $300-\mu \mathrm{g}$ Onbrez Breezhaler ${ }^{\circledR}$ products were identified by analysing the quantity of indacaterol maleate in the capsule. The contents of each capsule were emptied into a $100-\mathrm{mL}$ volumetric flask, and then the empty capsule was added before the washing solution. Six capsules were taken randomly from each pack of indacaterol 150 and $300 \mu \mathrm{g}$, and each solution was assayed in duplicate using the HPLC method described above. The coefficient of variation (\% CV) was used to assess the homogeneity of indacaterol 150 and $300 \mu \mathrm{g}$ powder formulations.

\section{Data Analysis}

The Copley Inhaler Testing Data Analysis Software (CITDAS version 2.0, Copley Scientific Ltd., UK) was used to calculate the aerodynamic dose emission parameters.

When using the ACI, the TED was obtained from the cumulative amounts of indacaterol deposited in the induction port (USP throat), the pre-separator and all the stages of the ACI. The fine particle dose (FPD) of indacaterol was the mass associated with particles $<5 \mu \mathrm{m}$. The fine particle dose was expressed as the percentage of the label claim, and the fine particle fraction (FPF) was the FPD divided by the TED. The mass median aerodynamic diameter (MMAD) was the size corresponding to the 50th percentile of the cumulative mass-weighed distribution of the amount deposited in the ACI. The TRD was calculated as the sum of the TED and the RA.

A one-way analysis of variance (ANOVA) was used to compare ED1, ED2, TED, RA, FPD, \% FPF and MMAD over the range of inhalation flow rates and volumes.

A two-way ANOVA was used to compare the emitted dose after one and two inhalations; in addition, Tukey's test was used to determine the difference in the ED, RA, TED, TRD, FPD, \%FPF and MMAD at different inhalation flows and volumes.

\section{RESULTS AND DISCUSSION}

The Onbrez Breezhaler ${ }^{\circledR}$ formulation, like many DPI devices, contains a blend of the micronised drug with $\alpha$ lactose monohydrate carrier. Each capsule contains indacaterol maleate equivalent to 150 or $300 \mu \mathrm{g}$ indacaterol. Onbrez Breezhaler ${ }^{\circledR} 150$ and $300 \mu \mathrm{g}$ are formulated with 
Table I. Mean, Percent Recovery and \% Coefficient of Variation (\% CV) in Indacaterol Maleate Content Contained in a Single Unit 150 and $300 \mu \mathrm{g}$ Indacaterol Onbrez Breezhaler ${ }^{\circledR}(n=6)$

\begin{tabular}{llc}
\hline $\begin{array}{l}\text { Indacaterol maleate } \\
\text { dose strength }\end{array}$ & $\begin{array}{l}\text { Mean dose per } \\
\text { capsule } \pm \mathrm{SD}\end{array}$ & $\% \mathrm{CV}$ \\
\hline $150 \mu \mathrm{g}$ & $151.32 \pm 2.68$ & 1.77 \\
$300 \mu \mathrm{g}$ & $301.46 \pm 4.74$ & 1.57 \\
\hline
\end{tabular}

similar amounts of carrier, i.e. $24.8 \mathrm{mg}$ for the $150-\mu \mathrm{g}$ indacaterol and $24.6 \mathrm{mg}$ for the $300-\mu \mathrm{g}$ dose (21), corresponding to a $0.6 \% \mathrm{w} / \mathrm{w}$ and $1.2 \% \mathrm{w} / \mathrm{w}$ drug/lactose ratio for 150 and $300 \mu \mathrm{g}$ indacaterol, respectively. SEM micrographs of the indacaterol formulations are shown in Supplement 1. This figure shows that the carrier particles for $150 \mu \mathrm{g}$ are much smaller than the $300-\mu \mathrm{g}$ indacaterol formulation, with the majority of carrier particles smaller than $50 \mu \mathrm{m}$. The SEM close view reveals the presence of tomahawk-shaped carrier with associated fine particles $\leq 5 \mu \mathrm{m}$ (Supplement 1c and d). The lactose carrier forms the major proportion of the DPI formulation, and any change in the physio-chemical properties of the carrier particles such as the size, shape, surface texture, grade and polymorphic form has the potential to alter drug deposition profile $(22,23)$. The particle size distribution (PSD) of indacaterol DPI formulations 150 and $300 \mu \mathrm{g}$ at different primary pressures measured using a Sympatec HELLOS/RODOS dry dispersion laser diffraction is shown in the figures (Supplements 2 and 3), respectively. The figures showed a broad PSD for both indacaterol formulations containing particles in the size range from approximately 1.5 to $70 \mu \mathrm{m}$. The primary pressure used was not sufficient to affect the shape of the size distribution. Nevertheless, it affected the particles' distribution density. The density of fine particles increased with the primary pressure increase which could occur as result of the breakage of agglomerates (Supplements 2 and 3). Despite the differences observed in the carrier particle size, size distribution and drug to carrier ratio, yet both formulations produced a good drug content uniformity ( $\% \mathrm{CV}<1.8 \%)$ and a percentage recovery of $100 \%$ (Table I).

Tables II and III summarise the dose emission results after the first (ED1) and after the second inhalation (ED2) as well as the TED for the 150- and 300- $\mu \mathrm{g}$ indacaterol products as a function of MIF and Vin. The ED1 significantly increased $(p<0.05)$, whereas the ED2 decreased with increasing of the MIF and Vin. At the low inhalation flow rate $(28.3 \mathrm{~L} / \mathrm{min})$, the first inhalation was not sufficient to withdraw most of the dose from the capsule and the second inhalation was necessary to empty the capsule (Fig. 1). The results confirm the recommendation to make two separate inhalations (1) especially when the low flow rate is used. The Vin contributed to the capsule emptying after the first inhalation. At the higher inhalation flow rate $(120 \mathrm{~L} / \mathrm{min})$, most of the dose was emitted from the capsule after the first inhalation, and only small amounts of the drug were left in the capsule after the second inhalation (Tables II and III). The impact of the inhaled volume with regard to dose emptying was more pronounced at the low flow rate

Table II. Mean (SD) of Dose Emission Data of $150 \mu \mathrm{g}$ Indacaterol Dose after Two Separate Inhalations

\begin{tabular}{|c|c|c|c|c|c|}
\hline Vin $(\mathrm{mL})$ & ED1 $(\mu \mathrm{g})$ & ED2 $(\mu \mathrm{g})$ & TED $(\mu \mathrm{g})$ & TRA $(\mu \mathrm{g})$ & TRD $(\mu \mathrm{g})$ \\
\hline \multicolumn{6}{|c|}{ Inhalation flow rate $28.3 \mathrm{~L} / \mathrm{min}$} \\
\hline 500 & $96.26(1.89)$ & $22.68(1.74)$ & $118.94(2.72)$ & $31.63(2.51)$ & $150.57(0.37)$ \\
\hline 750 & $104.90(2.01)$ & $18.40(1.65)$ & $123.30(0.76)$ & $28.41(1.52)$ & $151.71(1.86)$ \\
\hline 1000 & $114.98(2.71)$ & $9.72(0.66)$ & $124.70(3.27)$ & $20.05(0.23)$ & $144.75(3.24)$ \\
\hline 1500 & $121.23(3.08)$ & $6.58(1.92)$ & $127.81(1.16)$ & $17.78(0.38)$ & $145.59(1.12)$ \\
\hline 2000 & $123.13(3.07)$ & $4.44(0.56)$ & $127.57(2.68)$ & $17.88(0.80)$ & $145.45(5.03)$ \\
\hline \multicolumn{6}{|c|}{ Inhalation flow rate $60 \mathrm{~L} / \mathrm{min}$} \\
\hline 500 & $120.14(5.26)$ & $10.50(1.27)$ & $130.64(6.46)$ & $19.43(0.65)$ & $150.07(7.04)$ \\
\hline 750 & $123.90(2.41)$ & $7.72(2.86)$ & $131.62(1.57)$ & $18.15(0.88)$ & $149.77(2.27)$ \\
\hline 1000 & $129.16(3.36)$ & $4.75(0.66)$ & $133.91(3.11)$ & $15.97(0.61)$ & $149.88(3.11)$ \\
\hline 1500 & $131.73(4.10)$ & $3.72(0.91)$ & $135.45(4.65)$ & $13.79(0.70)$ & $149.24(5.28)$ \\
\hline 2000 & $134.27(4.32)$ & $2.50(0.70)$ & $136.77(3.96)$ & $13.37(0.75)$ & $150.14(4.25)$ \\
\hline \multicolumn{6}{|c|}{ Inhalation flow rate $90 \mathrm{~L} / \mathrm{min}$} \\
\hline 500 & $125.83(4.58)$ & $8.76(2.02)$ & $134.59(3.84)$ & $14.76(1.54)$ & $149.35(2.97)$ \\
\hline 750 & $128.16(3.62)$ & $7.19(1.61)$ & $135.35(5.23)$ & $13.37(0.14)$ & $148.72(5.10)$ \\
\hline 1000 & 133.87 (1.63) & 3.07 (1.19) & $136.94(2.38)$ & $13.33(0.09)$ & $150.27(2.45)$ \\
\hline 1500 & $136.08(4.45)$ & $2.13(0.63)$ & $138.21(3.92)$ & $12.50(0.24)$ & $150.71(5.52)$ \\
\hline 2000 & $137.15(4.93)$ & $1.92(0.95)$ & $139.07(5.76)$ & $12.22(0.73)$ & $151.29(3.48)$ \\
\hline \multicolumn{6}{|c|}{ Inhalation flow rate $120 \mathrm{~L} / \mathrm{min}$} \\
\hline 500 & 130.18 (4.37) & $6.24(1.59)$ & $136.42(5.32)$ & $12.42(0.92)$ & $148.84(6.18)$ \\
\hline 750 & $136.03(4.77)$ & $3.41(0.94)$ & $139.45(5.40)$ & $11.33(1.80)$ & $150.77(7.12)$ \\
\hline 1000 & 138.07 (7.98) & $3.41(1.64)$ & $141.48(3.39)$ & $11.71(1.63)$ & $153.19(8.00)$ \\
\hline 1500 & $140.42(6.98)$ & $2.76(0.47)$ & $143.17(6.55)$ & $9.94(0.54)$ & $153.12(6.62)$ \\
\hline 2000 & $142.43(1.94)$ & $1.28(0.73)$ & $143.71(1.74)$ & $8.65(0.89)$ & $152.36(2.53)$ \\
\hline
\end{tabular}


Table III. Mean (SD) of Dose Emission Data of $300 \mu \mathrm{g}$ Indacaterol Dose after Two Separate Inhalations

\begin{tabular}{|c|c|c|c|c|c|}
\hline Vin $(\mathrm{mL})$ & ED1 $(\mu \mathrm{g})$ & $\mathrm{ED} 2(\mu \mathrm{g})$ & TED $(\mu \mathrm{g})$ & TRA $(\mu \mathrm{g})$ & TRD $(\mu \mathrm{g})$ \\
\hline \multicolumn{6}{|c|}{ Inhalation flow rate $28.3 \mathrm{~L} / \mathrm{min}$} \\
\hline 500 & 199.15 (12.86) & $35.07(5.51)$ & $234.21(9.46)$ & $57.20(1.40)$ & $291.41(13.84)$ \\
\hline 750 & $214.89(12.81)$ & $32.25(1.84)$ & $247.14(14.20)$ & $47.71(1.45)$ & $294.85(10.03)$ \\
\hline 1000 & $242.03(11.55)$ & $11.49(5.13)$ & $253.52(11.00)$ & $36.16(0.84)$ & $289.68(11.42)$ \\
\hline 1500 & $244.82(12.01)$ & $9.68(3.34)$ & $254.51(10.47)$ & $35.50(1.60)$ & $290.01(14.74)$ \\
\hline 2000 & $249.43(11.15)$ & $5.74(1.77)$ & $255.17(11.98)$ & $31.47(1.13)$ & $286.63(13.10)$ \\
\hline \multicolumn{6}{|c|}{ Inhalation flow rate $60 \mathrm{~L} / \mathrm{min}$} \\
\hline 500 & $228.89(9.28)$ & $19.66(8.79)$ & $248.55(13.59)$ & $42.94(1.40)$ & $291.49(12.91)$ \\
\hline 750 & $242.91(5.23)$ & $9.34(2.13)$ & $252.25(6.91)$ & $38.74(1.33)$ & $290.99(8.22)$ \\
\hline 1000 & $253.20(11.25)$ & $5.17(1.05)$ & $258.37(10.25)$ & $35.42(0.44)$ & $293.79(10.32)$ \\
\hline 1500 & $255.77(7.15)$ & $4.03(2.07)$ & $259.80(15.83)$ & $32.70(0.78)$ & $292.50(11.07)$ \\
\hline 2000 & $259.17(9.53)$ & $3.40(0.56)$ & $262.57(9.61)$ & $30.47(2.07)$ & $293.04(11.89)$ \\
\hline \multicolumn{6}{|c|}{ Inhalation flow rate $90 \mathrm{~L} / \mathrm{min}$} \\
\hline 500 & $253.98(3.46)$ & $11.78(2.44)$ & $265.76(1.91)$ & 33.07 (1.17) & $298.83(7.84)$ \\
\hline 750 & $264.76(7.36)$ & $8.75(5.51)$ & $273.51(8.65)$ & $26.65(1.14)$ & $300.16(9.60)$ \\
\hline 1000 & $270.32(6.58)$ & $5.04(1.79)$ & $275.36(4.79)$ & $24.63(1.69)$ & $299.99(6.48)$ \\
\hline 1500 & $274.72(7.18)$ & $2.81(0.72)$ & $277.53(6.73)$ & $22.94(1.20)$ & $300.47(7.00)$ \\
\hline 2000 & $276.45(8.63)$ & $2.83(1.56)$ & $279.28(7.19)$ & $23.77(1.15)$ & $303.05(6.24)$ \\
\hline \multicolumn{6}{|c|}{ Inhalation flow rate $120 \mathrm{~L} / \mathrm{min}$} \\
\hline 500 & $261.25(11.38)$ & $8.84(0.16)$ & $270.10(19.22)$ & $22.46(1.72)$ & $292.55(1.87)$ \\
\hline 750 & $268.31(4.21)$ & $5.61(0.64)$ & $273.92(4.77)$ & $19.82(1.71)$ & $293.75(6.44)$ \\
\hline 1000 & $270.58(3.57)$ & $5.02(0.37)$ & $275.59(3.19)$ & $19.02(0.80)$ & $294.62(2.99)$ \\
\hline 1500 & $278.02(12.89)$ & $3.18(0.98)$ & $281.20(13.51)$ & $15.60(1.90)$ & $296.80(10.69)$ \\
\hline 2000 & $280.87(12.04)$ & $2.91(0.99)$ & $283.79(13.03)$ & $12.80(1.17)$ & $296.58(13.20)$ \\
\hline
\end{tabular}

(Tables II and III). It is widely accepted that breathactivated DPIs are often associated with flow ratedependent changes in the emitted dose (24-27). Increasing the MIF from 28.3 to $120 \mathrm{~L} / \mathrm{min}$ resulted in a significant $(p<0.05)$ increase in the total emitted dose.

Overall dose emission was reduced below a MIF of $60 \mathrm{~L} /$ min and Vin of $1 \mathrm{~L}$. Since the reported MIF and Vin of some COPD patients were found to be below these values $(8,16,17)$, then not all patients will inhale the prescribed dose when using the Onbrez Breezhaler ${ }^{\circledR}$.

The resistance of a DPI can be classified with respect to the inhalation flow required to produce a pressure drop of $4 \mathrm{kPa}$. This value was chosen because it is the one recommended by pharmacopoeia (20) for the in vitro characterisation of the dose emitted from a DPI. A device that is characterised as having a low resistance requires an inspiratory flow of $90 \mathrm{~L} / \mathrm{min}$ to produce this pressure drop (1). We found that the flow rate required to achieve a $4-\mathrm{kPa}$ pressure drop through the Breezhaler ${ }^{\circledR}$ was around $100 \mathrm{~L} / \mathrm{min}$ which is in line with $(17,28)$. This confirms that the Breezhaler ${ }^{\circledR}$ is a low-resistance device.

In the case of the indacaterol Breezhaler ${ }^{\circledR}$, irrespective of the sampling apparatus used (DUSA or ACI), the TED is almost doubled with increasing indacaterol dose from 150 to $300 \mu \mathrm{g}$, suggesting a linear relationship between the inhaled dose and the delivered dose in vitro. The $\mathrm{TED}_{\mathrm{ACI}}$ is equivalent to ED1 recovered from DUSA1. At the same MIF (90 L/min) and Vin $(2 \mathrm{~L})$, the $\mathrm{TED}_{\mathrm{ACI}}$ was generally smaller than ED1. The ACI is composed of many stages, and there will always be some drug losses during the washing procedure of the ACI, whereas the DUSA is relatively easy to wash and obtains up to $100 \%$ drug recovery. The washing procedure of either DUSA or ACI was carefully conducted as shown from the TRD which was around $100 \%$ for DUSA (Tables II and III) and $>92 \%$ for ACI (Tables IV and V).

Capsule-based DPIs can be limited by powder retention in the capsule and device, which leads to a reduction in the emitted dose (29). The drug retention could be minimised by coating the drug capsule and delivery device with pharmaceutically acceptable force-control agents (30). Irrespective of the dose strength, the residual amount in the capsule after two separate inhalations (RA/Cap), residual amount in the device (RA/Dev) and the total residual amount in capsule and device (TRA/RA(Cap) + RA(Dev)) were decreased with increasing of MIF and Vin (Tables II and III). The RA(Cap) after two separate inhalations is much smaller than the RA(Dev). Thus, inhaling twice from the capsule, inhaling forcefully and prolonging the inhalation time contribute all to the reduction in the TRA. The $\mathrm{RA}$ is about twofold for $300 \mu \mathrm{g}$ indacaterol (Table III) in comparison to $150 \mu \mathrm{g}$ using DUSA (Table II) or ACI (Tables IV and V).

The inhaled volumes used to quantify the aerodynamic particle size distribution of inhaled indacaterol exceed the internal volume of the ACI (1155 mL) (31) to allow sufficient sampling time for the aerosol bolus transfer from the inhaler device to distal stages of the ACI. The ACI data illustrate the impact of the Vin and MIF increase on the aerodynamic characteristics of indacaterol emitted dose. The results of the FPD as a function of the Vin at different MIFs for both dose strengths 150 and $300 \mu \mathrm{g}$ are shown in Fig. 2a, b, respectively. The FPD significantly $(p<0.05)$ increased with both the Vin and the MIF irrespective of the 

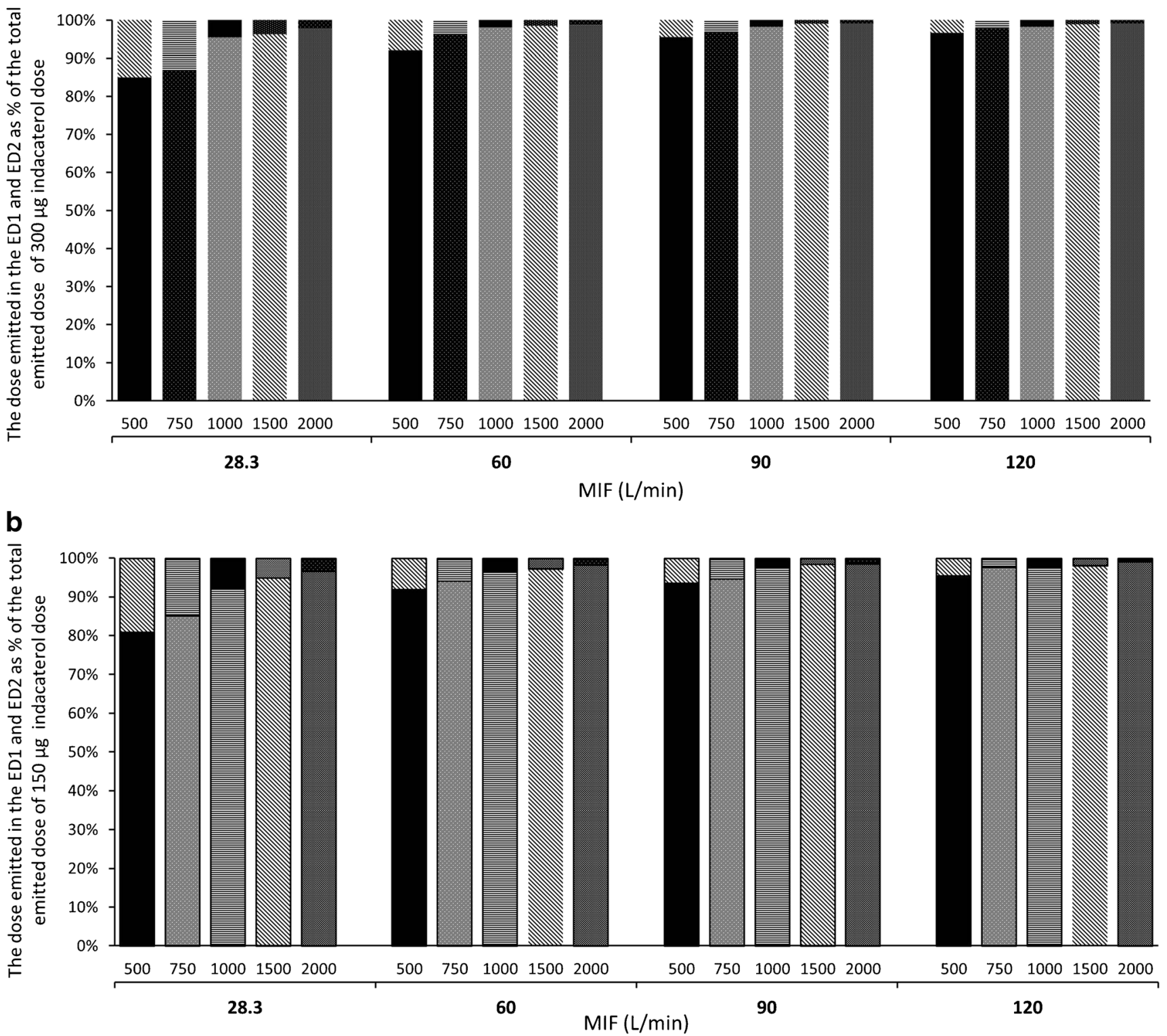

Fig. 1. The dose emission of indacaterol after one (ED1) and two (ED2) inhalations as percentage of the nominal dose. a The results of dose emission after two inhalations using indacaterol $300 \mu \mathrm{g}$ dose strength. b The results of dose emission using indacaterol $150 \mu \mathrm{g}$ dose strength

dose strength. The FPD was almost doubled when the dose strength increased from 150 to $300 \mu \mathrm{g}$ (Fig. 2a, b) across all MIFs and Vins; however, as a percentage of the nominal dose, the FPD would be almost similar for both dose strengths suggesting the reliability of the Breezhaler in delivering a consistent drug dosing in vitro. Prolonging the Vin is more critical especially when low MIF is used. For example, using an inhaled volume of $4 \mathrm{~L}$ at $28.3 \mathrm{~L} / \mathrm{min}$ would provide similar FPD to $90 \mathrm{~L} / \mathrm{min}$ and $1 \mathrm{~L}$ inhaled volume (Fig. 2). Thus, prolonging the inhalation volume is essential when high MIF cannot be achieved. The increase in FPD is more pronounced between 28.3 and $60 \mathrm{~L} / \mathrm{min}$, and the rate of increase in the FPD between 60 and $90 \mathrm{~L} / \mathrm{min}$ is generally reduced. Thus, $60 \mathrm{~L} / \mathrm{min}$ could be considered as a threshold MIF to operate the Breezhaler, which can be achieved easily achieved in practice due to the low resistance of this device. For example, using the same patients, a mean peak inspiratory flow (PIF) of $72 \mathrm{~L} / \mathrm{min}$ was generated with the Breezhaler ${ }^{\circledR}$ device compared with a mean PIF of only $36 \mathrm{~L} / \mathrm{min}$ with the HandiHaler ${ }^{\circledR}$ (32). The results of the EFPD $(<3 \mu \mathrm{m})$ for both dose strengths $(150$ and $300 \mu \mathrm{g})$ are shown in Fig. 3. A similar trend was observed for EFPD $(<3 \mu \mathrm{m})$ for both dose strengths with increasing the MIFs and Vins. The high proportion of EFPDs would improve the deposition in the peripheral airways in the lungs, and this is considered beneficial for the management of COPD $(33,34)$. Our study showed that both the MIFs and Vins are important in maximising the EFPD of indacaterol (Fig. 3). GSD values are $>1.2 \mu \mathrm{m}$ (Tables IV and $\mathrm{V}$ ) suggesting polydispersity of the aerosol; this 
Table IV. Mean (SD) of the Aerodynamic Characteristics of the Indacaterol 150- $\mu$ g Dose Emission at Different MIFs and Vins $[n=3]$

\begin{tabular}{|c|c|c|c|c|c|c|c|c|}
\hline Vin $(m L)$ & FPD $(\mu \mathrm{g})$ & TED $(\mu \mathrm{g})$ & $\%$ FPF & EFPD $(\mu \mathrm{g})$ & $\mathrm{RA}(\mu \mathrm{g})$ & $\%$ TRD & MMAD $(\mu \mathrm{m})$ & GSD \\
\hline \multicolumn{9}{|c|}{$\mathrm{MIF}=28.3 \mathrm{~L} / \mathrm{min}$} \\
\hline 1000 & $36.4(0.4)$ & $105.7(1.5)$ & $34.5(0.2)$ & $20.1(0.1)$ & $29.3(1.3)$ & $90.0(1.4)$ & $3.5(0.1)$ & $1.8(0.1)$ \\
\hline 1500 & $40.5(0.2)$ & $111.6(0.9)$ & $36.3(0.4)$ & $21.5(0.4)$ & $22.3(0.8)$ & $89.3(0.9)$ & $3.4(0.0)$ & $1.9(0.0)$ \\
\hline 2000 & $42.9(0.1)$ & $115.4(1.3)$ & $37.2(0.3)$ & $25.2(0.1)$ & $21.7(1.3)$ & $91.4(1.1)$ & $3.3(0.1)$ & $1.8(0.1)$ \\
\hline 4000 & $46.8(0.5)$ & $120.0(0.8)$ & $39.1(0.1)$ & $27.6(0.0)$ & $18.9(0.4)$ & $92.6(0.7)$ & $3.2(0.1)$ & $1.8(0.1)$ \\
\hline \multicolumn{9}{|c|}{$\mathrm{MIF}=60 \mathrm{~L} / \mathrm{min}$} \\
\hline 1000 & $43.2(0.5)$ & 119.4 (1.1) & $36.2(0.7)$ & $28.6(0.2)$ & $21.7(2.1)$ & $94.1(1.0)$ & $2.9(0.1)$ & $1.9(0.1)$ \\
\hline 1500 & $45.7(0.3)$ & $120.4(0.7)$ & $37.9(0.3)$ & $30.7(0.3)$ & $18.6(0.6)$ & $92.7(0.6)$ & $2.9(0.1)$ & $2.0(0.1)$ \\
\hline 2000 & $47.7(0.9)$ & $121.2(0.3)$ & $39.4(0.5)$ & $31.6(0.3)$ & $18.1(0.7)$ & $92.9(0.3)$ & $2.9(0.0)$ & $2.1(0.0)$ \\
\hline 4000 & $50.9(0.1)$ & $123.9(0.4)$ & $41.1(0.5)$ & $34.1(0.1)$ & $17.5(0.4)$ & $94.3(1.2)$ & $2.8(0.1)$ & $2.0(0.1)$ \\
\hline \multicolumn{9}{|c|}{$\mathrm{MIF}=90 \mathrm{~L} / \mathrm{min}$} \\
\hline 1000 & $45.7(0.2)$ & $121.0(0.2)$ & $37.8(0.6)$ & $34.2(0.6)$ & $17.8(0.6)$ & $92.5(0.8)$ & $2.8(0.1)$ & $2.0(0.1)$ \\
\hline 1500 & $47.7(0.1)$ & $123.8(0.8)$ & $38.5(0.4)$ & $35.1(0.3)$ & $15.7(0.4)$ & $93.0(1.2)$ & $2.8(0.1)$ & $2.1(0.1)$ \\
\hline 2000 & $53.9(0.4)$ & $124.6(0.7)$ & $43.2(0.6)$ & $38.4(0.2)$ & $13.3(0.3)$ & $91.9(0.7)$ & $2.7(0.0)$ & $2.0(0.0)$ \\
\hline 4000 & $54.7(0.4)$ & $126.2(0.3)$ & $43.4(0.9)$ & $39.1(0.9)$ & $12.7(0.7)$ & $92.6(1.5)$ & $2.7(0.0)$ & $2.0(0.0)$ \\
\hline
\end{tabular}

$F P D$ fine particle dose $(\leq 5 \mu \mathrm{m}), T E D$ total emitted dose, $F P F$ fine particle mass as percentage of the TED, EFPD extra fine particle dose $(\leq 3 \mu \mathrm{m}), R A$ residual amount (retained in capsule and device), \% TRD total recovery dose as percentage of the nominal dose $150 \mu \mathrm{g}$ indacaterol, MMAD mass median aerodynamic diameter, GSD geometric standard deviation, MIF maximum inhalation flow, Vin inhaled volume

polydispersity is more likely to influence drug distribution in the airways. This polydispersity contains substantial mass fractions of particles smaller than $5 \mu \mathrm{m}$ (Fig. 4a, b). The greatest decrease in MMAD was observed between 28.3 and $60 \mathrm{~L} / \mathrm{min}$ across all Vins used, and the increase of the MIF above $60 \mathrm{~L} / \mathrm{min}$ did not bring much difference in the MMAD, suggesting that $60 \mathrm{~L} / \mathrm{min}$ is the minimum MIF to operate the Breezhaler. An MMAD $<5 \mu \mathrm{m}$ is considered to be necessary for sufficient airway deposition (35). The differences in FPF $<5 \mu \mathrm{m}$ between different flow rates and volumes are also strongly reflected in the differences in the EFPF $(<3 \mu \mathrm{m})$. The turbulence generated at high flow rates
60 and $90 \mathrm{~L} / \mathrm{min}$ was able to generate sufficient shear forces between drug-drug particles. Such phenomenon would be able to enhance particle dispersion leading to the formation of smaller particle size (36) as shown in Fig. 3. Prolonging inhaled volume may have also provided particles with sufficient time of flight allowing drug-drug particle detachment. The performance of the Breezhaler is dependent on both inhalation flow rate and volume. The increase in FPD is more pronounced between 28.3 and $60 \mathrm{~L} / \mathrm{min}$. Prolonging the Vin is more critical especially when low MIF is used. The Breezhaler was effective in producing respirable particles with an MMAD $<5 \mu \mathrm{m}$ irrespective of the

Table V. Mean (SD) of the Aerodynamic Characteristics of the Indacaterol 300- $\mu \mathrm{g}$ Dose Emission at Different MIFs and Vins [ $n=3]$

\begin{tabular}{|c|c|c|c|c|c|c|c|c|}
\hline Vin $(m \operatorname{Vin}(\mathrm{mL})$ & FPD $(\mu \mathrm{g})$ & TED $(\mu \mathrm{g})$ & $\% \mathrm{FPF}$ & EFPD $(\mu \mathrm{g})$ & $\mathrm{RA}(\mu \mathrm{g})$ & $\%$ TRD & MMAD $(\mu \mathrm{m})$ & GSD \\
\hline \multicolumn{9}{|l|}{$\mathrm{MIF}=28.3 \mathrm{~L} / \mathrm{min}$} \\
\hline 1000 & $72.9(1.2)$ & $218.9(1.7)$ & $33.3(1.2)$ & $40.5(0.2)$ & $49.7(0.9)$ & $89.5(2.1)$ & $3.3(0.0)$ & $1.8(0.1)$ \\
\hline 1500 & $83.0(0.2)$ & $231.0(1.4)$ & $36.0(0.3)$ & $45.3(0.5)$ & $39.2(1.1)$ & $90.0(0.9)$ & $3.3(0.1)$ & $1.9(0.1)$ \\
\hline 2000 & $86.3(0.4)$ & $232.0(1.2)$ & $37.2(0.2)$ & $48.3(0.3)$ & $38.1(0.7)$ & $90.1(1.1)$ & $3.2(0.0)$ & $1.9(0.0)$ \\
\hline 4000 & $89.8(1.3)$ & $236.1(1.0)$ & $38.0(0.3)$ & $50.0(0.1)$ & $35.5(1.3)$ & $90.5(1.6)$ & $3.0(0.1)$ & $1.8(0.0)$ \\
\hline \multicolumn{9}{|l|}{$\mathrm{MIF}=60 \mathrm{~L} / \mathrm{min}$} \\
\hline 1000 & $92.5(0.4)$ & $240.9(2.0)$ & $38.4(0.4)$ & $62.6(0.5)$ & $36.3(1.0)$ & $92.4(2.0)$ & $2.8(0.0)$ & $2.0(0.1)$ \\
\hline 1500 & $96.0(0.5)$ & $245.4(1.3)$ & $39.1(0.6)$ & $64.4(0.3)$ & $33.1(1.2)$ & $92.8(1.1)$ & $2.8(0.1)$ & $2.1(0.1)$ \\
\hline 2000 & $99.8(0.9)$ & $247.8(1.5)$ & $40.3(0.7)$ & $66.1(0.3)$ & $32.9(0.8)$ & $93.6(1.3)$ & $2.7(0.1)$ & $2.0(0.1)$ \\
\hline 4000 & $106.4(0.6)$ & $249.5(0.7)$ & $42.7(0.5)$ & $68.8(0.8)$ & $31.5(0.6)$ & $93.6(1.9)$ & $2.7(0.0)$ & $2.1(0.0)$ \\
\hline \multicolumn{9}{|l|}{$\mathrm{MIF}=90 \mathrm{~L} / \mathrm{min}$} \\
\hline 1000 & $95.5(1.2)$ & $244.1(1.1)$ & $39.1(0.8)$ & $74.0(0.6)$ & $34.6(0.9)$ & $92.9(1.2)$ & $2.7(0.1)$ & $2.0(0.1)$ \\
\hline 1500 & $105.3(0.8)$ & $246.5(0.9)$ & $42.7(0.7)$ & $79.0(0.3)$ & $30.5(0.4)$ & $92.3(1.0)$ & $2.7(0.0)$ & $1.8(0.0)$ \\
\hline 2000 & $108.5(0.4)$ & $247.4(0.7)$ & $43.9(0.6)$ & $81.1(0.2)$ & $31.1(0.8)$ & $92.8(0.7)$ & $2.6(0.1)$ & $1.9(0.1)$ \\
\hline 4000 & $112.6(0.7)$ & $252.1(1.0)$ & $44.7(0.9)$ & $82.1(0.9)$ & $29.1(0.5)$ & $93.7(0.8)$ & $2.6(0.1)$ & $1.9(0.1)$ \\
\hline
\end{tabular}

fine particle dose $(\leq 5 \mu \mathrm{m}), T E D$ total emitted dose, $F P F$ fine particle mass as percentage of the TED, EFPD extra fine particle dose $(\leq 3 \mu \mathrm{m})$, $R A$ residual amount (retained in capsule and device), \% TRD total recovery dose as percentage of the nominal dose $300 \mu \mathrm{g}$ indacaterol, $M M A D$ mass median aerodynamic diameter, GSD geometric standard deviation, MIF maximum inhalation flow, Vin inhaled volume 

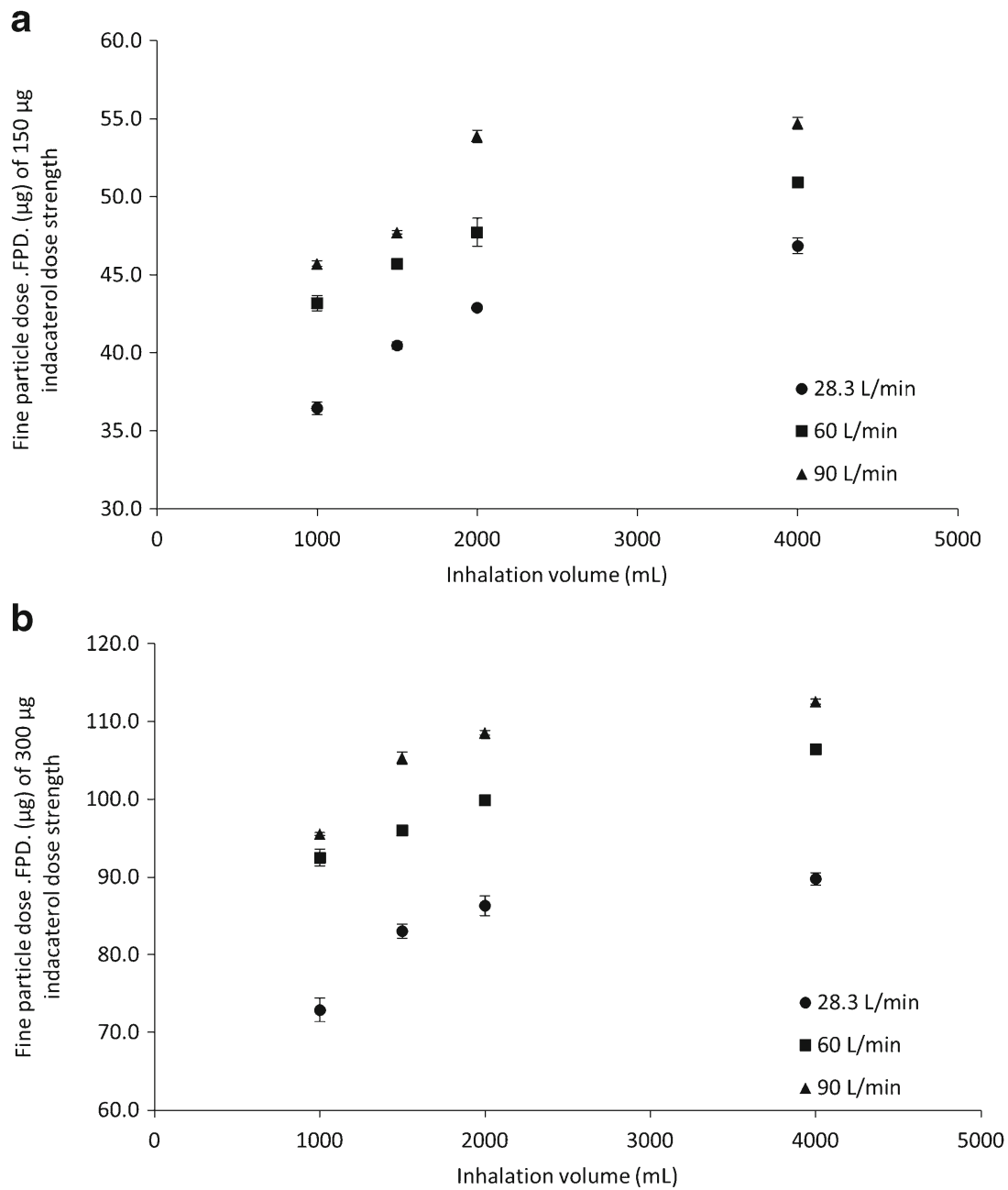

Fig. 2. The fine particle dose $(F P D)$ of indacaterol emitted from the Onbrez Breezhaler ${ }^{\circledR}$ at different MIFs of 28.3, 60 and $90 \mathrm{~L} / \mathrm{min}$ and Vins of 1, 1.5, 2 and $4 \mathrm{~L}$ for both a $150 \mu \mathrm{g}$ dose strength and $\mathbf{b} 300 \mu \mathrm{g}$ dose strength

inhalation flow rate, but the mass fraction of particles with an aerodynamic diameter $<3 \mu \mathrm{m}$ is more pronounced between 60 and $90 \mathrm{~L} / \mathrm{min}$ as shown in Fig. 4. The difference in the drug particle size distribution as a function of the flow rate and volume is more likely to influence drug distribution in the airways.

\section{CONCLUSIONS}

The indacaterol dose emission from the capsule-based Onbrez Breezhaler ${ }^{\circledR}$ for both dose strengths 150 and $300 \mu \mathrm{g}$ demonstrated inhalation flow-dependent dose emission. Furthermore, the Vin was important when low MIF was used. The aerodynamic characteristics of indacaterol showed that Breezhaler ${ }^{\circledR}$ was effective in producing respirable particles with an MMAD $<5 \mu \mathrm{m}$ irrespective of the inhalation flow rate, but the mass fraction of particles with an aerodynamic diameter $<3 \mu \mathrm{m}$ is more pronounced between 60 and $90 \mathrm{~L} / \mathrm{min}$. The difference in the drug particle size distribution as a function of the flow rate and volume is more likely to influence drug distribution in the airways.

Overall, the results suggest that a minimum MIF of $60 \mathrm{~L} / \mathrm{min}$ and inhaled volume are required when using the indacaterol Breezhaler ${ }^{\circledR}$. Finally, the results confirm the recommendation of using two separate inhalations for each dose, although this is less important at high MIF and Vin.

ED1 dose emitted after the first inhalation, ED2 dose emitted after the second inhalation, DUSA dose unit sampling apparatus, $A C I$ Andersen cascade impactor, $D P I s$ dry powder inhalers, $E D$ emitted dose, $F P D$ fine particle dose, $F P F$ fine particle fraction, $T R D$ total recovered dose, HPLC high-performance liquid chromatography, $P I F R$ peak inhalation flow rate, $I T$ inhalation time, Vin inhaled volume, TED total emitted dose, $L O D$ limit of detection, $L O Q$ limit of quantification, $M M A D$ mass median aerodynamic diameter, $M I F$ maximum inhalation flow, $P I L$ patient information leaflets, $R A$ residual amount, SEM scanning electron microscope, TRA total residual amount, $P S D$ particle size distribution 


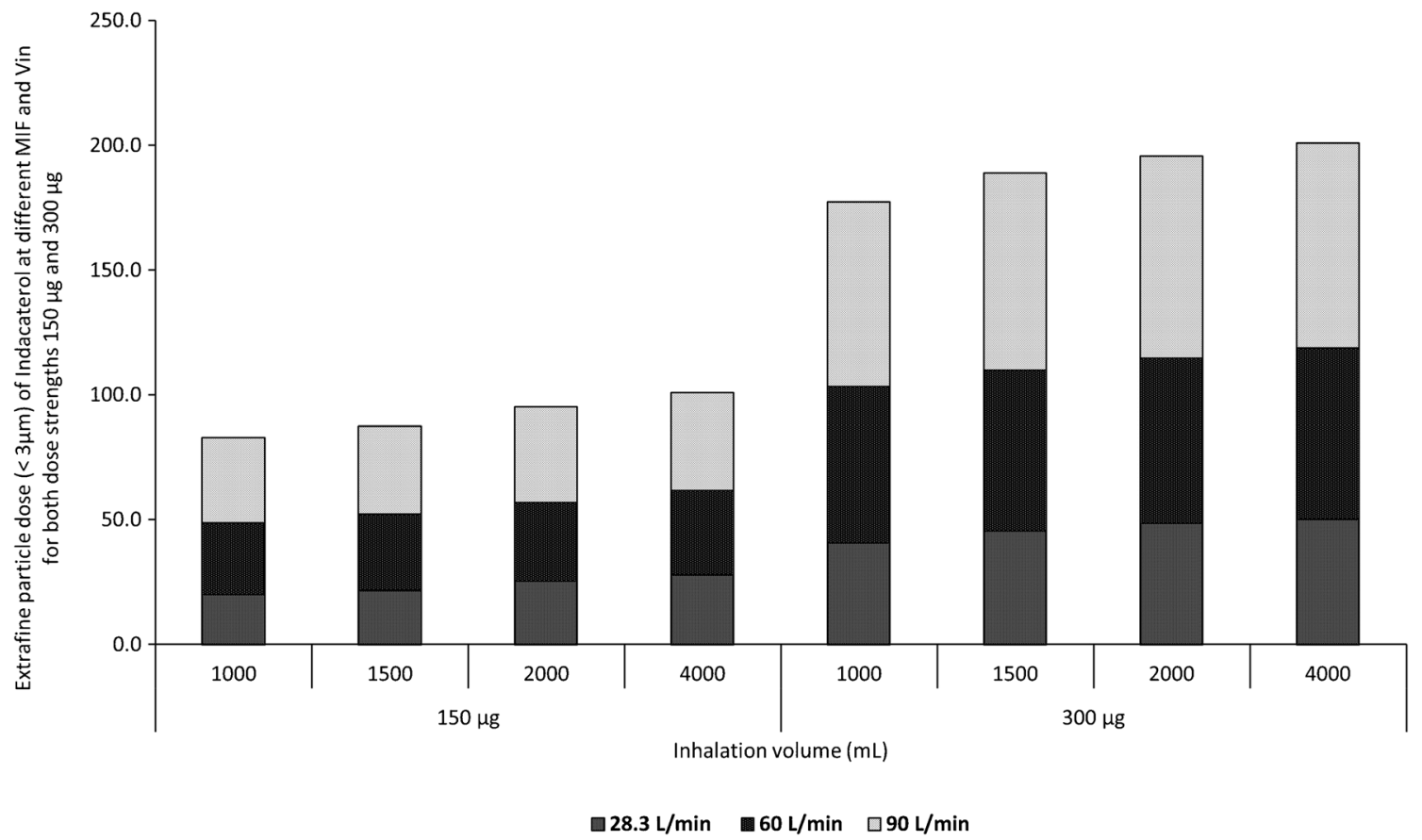

Fig. 3. The extra fine particle dose (EFPD) of indacaterol emitted from the Onbrez Breezhaler® as a function of the inhalation flow $(M I F)$ and volume (Vin) used for both dose strengths 150 and $300 \mu \mathrm{g}$

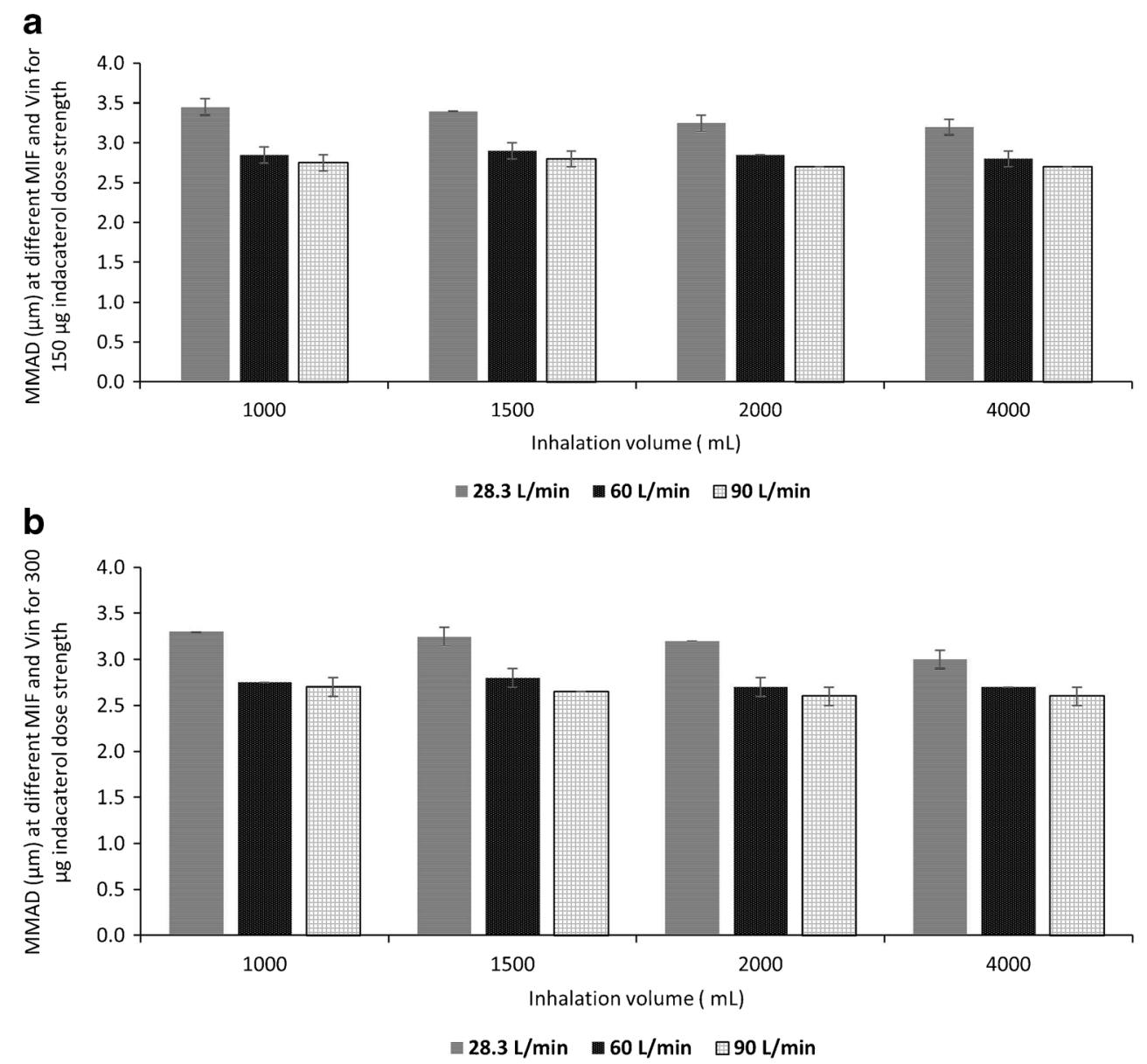

Fig. 4. The mass median aerodynamic diameter $(M M A D)$ of indacaterol emitted particles at different inhalation flow $(M I F)$ and inhalation volumes (Vin) for both a $150 \mu \mathrm{g}$ indacaterol dose strength and b $300 \mu \mathrm{g}$ indacaterol dose strength 


\section{COMPLIANCE WITH ETHICAL STANDARDS}

Conflict of Interest Henry Chrystyn has no shares in any pharmaceutical companies. He has received sponsorship to carry out studies, together with board membership, consultant agreements and honoraria for presentation, from several pharmaceutical companies that market inhaled products. These include Almirall, AstraZeneca, Boehringer Ingelheim, Chiesi, GlaxoSmithKline, Innovata Biomed, Meda, Napp Pharmaceuticals, Mundipharma, NorPharma, Novartis, Orion, Sanofi, Teva, Trudell Medical International, UCB and Zentiva. Research sponsorship has also been received from grant awarding bodies (EPSRC and MRC). He is the owner of Inhalation Consultancy Ltd. He is also a consultant for Research in Real Life, which is subcontracted by Observational and Pragmatic Research Institute Pte Ltd. The authors declare no conflicts of interest in this work.

Open Access This article is distributed under the terms of the Creative Commons Attribution 4.0 International License (http://creativecommons.org/licenses/by/4.0/), which permits unrestricted use, distribution, and reproduction in any medium, provided you give appropriate credit to the original author(s) and the source, provide a link to the Creative Commons license, and indicate if changes were made.

\section{REFERENCES}

1. Laube BL, Janssens HM, de Jongh FH, Devadason SG, Dhand $\mathrm{R}$, Diot $\mathrm{P}$, et al. What the pulmonary specialist should know about the new inhalation therapies. Eur Respir J. 2011;37(6):1308-417.

2. Clark A, Hollingworth A. The relationship between powder inhaler resistance and peak inspiratory conditions in healthy volunteers-implications for in vitro testing. J Aerosol Med. 1993;6(2):99-110.

3. Chrystyn H. Is inhalation rate important for a dry powder inhaler? Using the In-Check Dial to identify these rates. Respir Med. 2003;97(2):181-7.

4. Haughney J, Price D, Barnes NC, Virchow JC, Roche N, Chrystyn H. Choosing inhaler devices for people with asthma: current knowledge and outstanding research needs. Respir Med CME. 2010;3(3):125-31.

5. De Boer A, Bolhuis G, Gjaltema D, Hagedoorn P. Inhalation characteristics and their effects on in vitro drug delivery from dry powder inhalers: part 3: the effect of flow increase rate (FIR) on the in vitro drug release from the Pulmicort 200 Turbuhaler. Int J Pharm. 1997;153(1):67-77.

6. Dal Negro RW. Dry powder inhalers and the right things to remember: a concept review. Multidisciplinary respiratory medicine. 2015;10(1):1.

7. Al-Showair RA, Tarsin WY, Assi KH, Pearson SB, Chrystyn H. Can all patients with COPD use the correct inhalation flow with all inhalers and does training help? Respir Med. 2007;101(11):2395-401.

8. Chapman KR, Fogarty CM, Peckitt C, Lassen C, Jadayel D, Dederichs $\mathrm{J}$, et al. Delivery characteristics and patients' handling of two single-dose dry-powder inhalers used in COPD. Int J Chron Obstruct Pulmon Dis. 2011;6:353-63.

9. Azouz W, Chrystyn H. Clarifying the dilemmas about inhalation techniques for dry powder inhalers: integrating science with clinical practice. Prim Care Respir J. 2012;21(2):208-13.
10. Chrystyn H, Price DB, Molimard M, Haughney J, BosnicAnticevich S, Lavorini F, et al. Comparison of serious inhaler technique errors made by device-naïve patients using three different dry powder inhalers: a randomised, crossover, openlabel study. BMC Pulmonary Medicine. 2016;16(1):1.

11. Azouz W, Chetcuti P, Hosker H, Saralaya D, Chrystyn H. Inhalation characteristics of asthma patients, COPD patients and healthy volunteers with the Spiromax ${ }^{\mathbb{R}}$ ? and Turbuhaler ${ }^{\mathbb{B}}$ ? devices: a randomised, cross-over study. BMC Pulmonary Medicine. 2015;15(1):47.

12. Azouz W, Chetcuti P, Hosker HS, Saralaya D, Stephenson J, Chrystyn H. The inhalation characteristics of patients when they use different dry powder inhalers. J Aerosol Med Pulm Drug Deliv. 2015;28(1):35-42.

13. Lavorini F, Usmani OS. Correct inhalation technique is critical in achieving good asthma control. Primary Care Respiratory Journal. 2013;22:385-6.

14. Cazzola M, Page C. Long-acting bronchodilators in COPD: where are we now and where are we going? Breathe. 2014;10(2):110-20.

15. Cazzola M, Matera MG, Lötvall J. Ultra long-acting $\beta 2$ agonists in development for asthma and chronic obstructive pulmonary disease. Expert Opin Investig Drugs. 2005;14(7):775-83.

16. Colthorpe P, Voshaar T, Kieckbusch T, Cuoghi E, Jauernig J. Delivery characteristics of a low-resistance dry-powder inhaler used to deliver the long-acting muscarinic antagonist glycopyrronium. Journal of Drug Assessment. 2013;2(1):11-6.

17. Pavkov R, Mueller S, Fiebich K, Singh D, Stowasser F, Pignatelli G, et al. Characteristics of a capsule based dry powder inhaler for the delivery of indacaterol. Curr Med Res Opin. 2010;26(11):2527-33.

18. Buttini F, Pasquali I, Brambilla G, Copelli D, Dagli Alberi M, Balducci AG, et al. Multivariate analysis of effects of asthmatic patient respiratory profiles on the in vitro performance of a reservoir multidose and a capsule-based dry powder inhaler. Pharm Res. 2016;33(3):701-15.

19. Jaffari S, Forbes B, Collins E, Barlow DJ, Martin GP, Murnane D. Rapid characterisation of the inherent dispersibility of respirable powders using dry dispersion laser diffraction. Int $\mathrm{J}$ Pharm. 2013;447(1):124-31.

20. US. United States Pharmacopeia, USP 38-NF 33. 2014.

21. Moen MD. Indacaterol. Drugs. 2010;70(17):2269-80.

22. Larhrib H, Zeng XM, Martin GP, Marriott C, Pritchard J. The use of different grades of lactose as a carrier for aerosolised salbutamol sulphate. Int J Pharm. 1999;191(1):1-14.

23. Zeng XM, Martin GP, Marriott C, Pritchard J. The influence of carrier morphology on drug delivery by dry powder inhalers. Int J Pharm. 2000;200(1):93-106.

24. Hill L, Slater A. A comparison of the performance of two modern multidose dry powder asthma inhalers. Respir Med. 1998;92(1):105-10.

25. Telko MJ, Hickey AJ. Dry powder inhaler formulation. Respir Care. 2005;50(9):1209-27.

26. Taylor A, Gustafsson P. Do all dry powder inhalers show the same pharmaceutical performance? Int J Clin Pract. 2005;59(s149):7-12.

27. Johal B, Howald M, Fischer M, Marshall J, Venthoye G. Fine particle profile of fluticasone propionate/formoterol fumarate versus other combination products: the DIFFUSE study. Comb Prod Ther. 2013;3(1-2):39-51.

28. Dederichs J, Singh D, Pavkov R. Inspiratory flow profiles generated by patients with COPD through the Breezhaler ${ }^{\circledR}$ ? inhaler and other marketed dry powder inhalers. D37 help: advances in COPD therapeutics. Am Thoracic Soc. 2015:A5793-A.

29. Vidgren M, Kärkkäinen A, Karjalainen P, Paronen P, Nuutinen J. Effect of powder inhaler design on drug deposition in the respiratory tract. Int J Pharm. 1988;42(1):211-6.

30. Heng D, Lee SH, Ng WK, Chan H-K, Kwek JW, Tan RB. Novel alternatives to reduce powder retention in the dry 
powder inhaler during aerosolization. Int $\mathrm{J}$ Pharm. 2013;452(1):194-200.

31. Copley M, Smurthwaite M, Roberts D, Mitchell J. Revised internal volumes of cascade impactors for those provided by Mitchell and Nagel. J Aerosol Med. 2005;18(3):364-6.

32. Price D, Chrystyn H. Concept review of dry powder inhalers: correct interpretation of published data. Multidisciplinary respiratory medicine. 2015;10(1):36.

33. Heyder J. Deposition of inhaled particles in the human respiratory tract and consequences for regional targeting in respiratory drug delivery. Proc Am Thorac Soc. 2004;1(4):315-20.
34. de Boer AH, Gjaltema D, Hagedoorn P, Frijlink HW. Can 'extrafine' dry powder aerosols improve lung deposition? Eur J Pharm Biopharm. 2015;96:143-51.

35. Roche N, Chrystyn H, Lavorini F, Agusti A, Virchow JC, Dekhuijzen R, et al. Effectiveness of inhaler devices in adult asthma and COPD. EMJ Respir. 2013;1:64-71.

36. Abadelah M, Hazim F, Chrystyn H, Bagherisadeghi G, Rahmoune H, Larhrib $\mathrm{H}$. Effect of maximum inhalation flow and inhaled volume on formoterol drug deposition in-vitro from an Easyhaler ${ }^{\circledR}$ ? dry powder inhaler. Eur J Pharm Sci. 2017;104:180-7. 